\title{
ПОВЕДЕНИЕ ЛЕНСКОГО ОСЕТРА ACIPENSER BAERII, BRANDT ПРИ ИСПОЛЬЗОВАНИИ НОВОГО ТИПА КОРМА
}

\author{
Е.Г. Скворцова (фото) \\ к.б.н., доцент, заведующая кафедрой зоотехнии \\ Ю.С. Уткина \\ аспирант кафедры зоотехнии \\ А.С. Демидова \\ обучающаяся технологического факультета \\ ФГБОУ ВО Ярославская ГСХА, г. Ярославль
}

Питание является одной из самых важных функций организма. За счёт энергетических веществ, поступающих в организм в виде пищи, происходят рост, развитие, размножение. В течение жизни рыбы затрачивают на проявление пищевого поведения от 10 до 48\% времени [1]. Пищевым поведением рыб называют сложный процесс последовательной смены отдельных поведенческих фаз и актов от момента получения информации о присутствии в среде кормовых объектов до принятия решения об их схватывании или отвергании [2].

По мнению учёных (Павлов, Касумян, 1990), схематически пищевое поведение рыб можно разделить на несколько фаз и этапов (табл. 1).

В данной работе ставилась задача исследовать влияние типа корма на пищевое поведение молоди ленского осетра, оценить поведе-

Investigative behavior, eating behavior, juvenile sturgeon, motion behavior ние особей в фазе ближнего поиска и обнаружения пищевого объекта. Исследования проводили методом периодов на одной группе рыб, 5 экземпляров.

\section{Материал и методика исследований}

Исследования проводили на базе ФГБОУ ВО Ярославская ГСХА. Объектом исследования служили годовики ленского осетра. Исследуемая выборка состояла из пяти особей (длина тела колебалась в диапазоне 12,1-15,4 см, масса тела - 10,0-20,2 г). Молодь рыб получена путём искусственного воспроизводства с последующим выращиванием в экспериментальном кубе с принудительной аэрацией. Температура воды $18-20^{\circ} \mathrm{C}$, освещение естественное. Рыб кормили 1 раз в сутки.

Опыты проводили по следующей схеме. Процесс кормления производили в одно и то же время суток в течение 6 дней. Рыбам предлагалось добыть кормовой объект - комбикорм (1-3 дни) и гидролизат белкового субстрата, полученный путём кислотного гидролиза из мышечной ткани леща (4-6 дни) в количестве 50 частей.

По химическому составу гидролизат является белковой кормовой добавкой для рыб с содержанием в натуральном веществе сырого протеина 22,7\%, сырого жира 3,2\% и сырой золы 26,6\% [5]. Комбикорм 
Таблица 1 - Фазы и этапы пищевого поведения рыб (Павлов, Касумян, 1990)

\begin{tabular}{|c|l|l|}
\hline Фазы & \multicolumn{1}{|c|}{$\begin{array}{c}\text { Поведенческое состояние } \\
\text { рыбы }\end{array}$} & \multicolumn{1}{c|}{ Примечание } \\
\hline 1 & Покой & $\begin{array}{l}\text { Во время болезни рыбы, в период зимовки или нереста, незадолго до } \\
\text { наступления и во время сейсмических или геомагнитных возмущений, } \\
\text { во время достижения рыбами определённой степени накормленности }\end{array}$ \\
\hline 2 & $\begin{array}{l}\text { Готовность к получению } \\
\text { огнала о наличии пищевого } \\
\text { объекта }\end{array}$ & $\begin{array}{l}\text { Повышение двигательной активности - рыба «сканирует» пространство } \\
\text { на наличие пищевых сигналов }\end{array}$ \\
\hline 4 & $\begin{array}{l}\text { Получение сигнала о присут- } \\
\text { ствии корма }\end{array}$ & $\begin{array}{l}\text { Возрастание активности рыбы, начало «прочесывания» местообитаний } \\
\text { с целью получения сигнала о наличии корма }\end{array}$ \\
\hline 5 & $\begin{array}{l}\text { Поиск и обнаружение источ- } \\
\text { коределение пригодности }\end{array}$ & $\begin{array}{l}\text { Эта фаза состоит из двух этапов: } \\
\text { а) дальнего поиска; } \\
\text { б) ближнего поиска и обнаружения источника сигнала }\end{array}$ \\
\hline & $\begin{array}{l}\text { Эта фаза также состоит из двух этапов: } \\
\text { а) этап схватывания пищи (предварительное решение о пригодности } \\
\text { корма); } \\
\text { б) этап заглатывания или отвергания пищи (окончательное решение } \\
\text { о пригодности корма) }\end{array}$ \\
\hline
\end{tabular}

NeoStart 3 - стартовый, полностью экструдированный корм для осетровых, в состав которого входит рыбная мука, соевая мука, пшеничный глютен, рыбий жир, пшеничная мука, кукурузный глютен, аминокислота, рапсовая мука, минералы, витамины (табл. 2).

Видиофиксация исследования составляла 3 минуты, потом анализировали видеозапись. Регистрировали три параметра [3]:

- латентное время питания - продолжительность поиска от заброса частиц пищевого объекта до достижения и захвата пищевых частиц рыбами в «кормовом пятне», с;
- рацион - количество пищевых частиц, съеденных за 3 минуты наблюдения, экз.;

- скорость питания (отношение рациона к суммарному времени питания), экз./с.

Производили биометрическую обработку полученных данных (нахождение средней арифметической величины (М), ошибки $(\mathrm{m})$; достоверность различий между контролем и опытами устанавливали с помощью t-критерия Стьюдента [4]) с помощью приложения Excel пакета программ Microsoft Office 2007. Дисперсионный анализ производили с помощью надстройки «Пакет анализа» Excel Microsoft Office 2007.

Таблица 2 - Содержание питательных веществ в полноценном комбикорме для молоди осетровых

\begin{tabular}{|l|c|}
\hline \multicolumn{1}{|c|}{ Наименование } & Значение \\
\hline Сырой протеин, \% & 47,0 \\
\hline Жир, \% & 18,0 \\
\hline Влажность, \% & 10,0 \\
\hline Сырая клетчатка, \% & 1,8 \\
\hline Фосфор,\% & 1,0 \\
\hline Зола, \% & 7,0 \\
\hline БЭВ, \% & 16,2 \\
А, М.Е. & 10000 \\
\hline DЗ, М.Е. & 1750 \\
\hline Е, мг & 200 \\
\hline С, мг & 150 \\
\hline Метионин + цистин, \% & 4,63 \\
\hline
\end{tabular}




\section{Результаты исследований}

Сравнительный анализ показателей, приведённый в таблице 3, показал, в какой мере молодь ленского осетра способна реагировать на разный тип корма.

При кормлении комбикормом в первый день

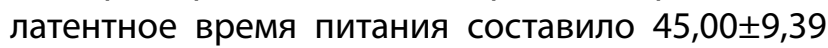

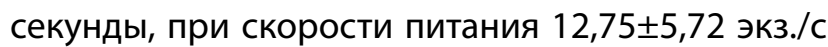

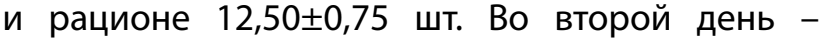
$47,00 \pm 5,75$ секунды, при скорости питания $2,50 \pm 0,33$ экз./с и рационе $8,75 \pm 1,91$ шт. В третий

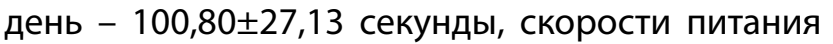

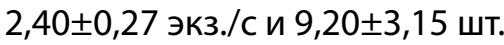

При кормлении гидролизатом в первый день латентное время питания составило $63,60 \pm 21,89$

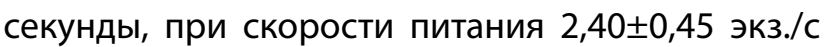

Таблица 3 - Особенности пищевого поведения ленского осетра при кормлении комбикормом и гидролизатом

\begin{tabular}{|c|c|c|c|c|c|c|c|c|}
\hline \multirow{2}{*}{ Показатель } & \multirow{2}{*}{ Вариант опыта } & \multicolumn{5}{|c|}{ Особь } & \multirow{2}{*}{$M \pm m$} & \multirow{2}{*}{$\sigma$} \\
\hline & & 1 & 2 & 3 & 4 & 5 & & \\
\hline \multirow{6}{*}{$\begin{array}{l}\text { Латентное } \\
\text { время пита- } \\
\text { ния }\left(\mathrm{V}_{\text {лат) }} \text { с }\right.\end{array}$} & Комбикорм, 1 день & 69 & 33 & 38 & 40 & 0 & $45,00 \pm 9,39$ & 16,27 \\
\hline & Комбикорм,2 день & 0 & 37 & 40 & 54 & 57 & $47,00 \pm 5,75$ & 9,97 \\
\hline & Комбикорм,3 день & 20 & 74 & 116 & 143 & 151 & $100,80 \pm 27,13$ & 54,27 \\
\hline & Гидролизат, 1 день & 6 & 48 & 53 & 90 & 121 & $63,60 \pm 21,89$ & 43,78 \\
\hline & Гидролизат, 2 день & 68 & 88 & 92 & 100 & 155 & $100,60 \pm 16,31$ & 32,62 \\
\hline & Гидролизат, 3 день & 21 & 26 & 38 & 76 & 91 & $50,40 \pm 15,65$ & 31,29 \\
\hline \multirow{6}{*}{$\begin{array}{l}\text { Скорость } \\
\text { питания }\left(\mathrm{V}_{\text {пит) }}\right. \\
\text { экз./с }\end{array}$} & Комбикорм, 1 день & 26 & 3 & 14 & 8 & 0 & $12,75 \pm 5,72$ & 9,91 \\
\hline & Комбикорм, 2 день & 0 & 3 & 2 & 3 & 2 & $2,50 \pm 0,33$ & 0,58 \\
\hline & Комбикорм, 3 день & 3 & 3 & 2 & 2 & 2 & $2,40 \pm 0,27$ & 0,55 \\
\hline & Гидролизат, 1 день & 2 & 2 & 4 & 2 & 2 & $2,40 \pm 0,45$ & 0,89 \\
\hline & Гидролизат, 2 день & 2 & 2 & 2 & 4 & 2 & $2,40 \pm 0,45$ & 0,89 \\
\hline & Гидролизат, 3 день & 2 & 4 & 3 & 3 & 2 & $2,80 \pm 0,42$ & 0,84 \\
\hline \multirow{6}{*}{$\begin{array}{l}\text { Рацион (R), } \\
\text { экз. }\end{array}$} & Комбикорм, 1 день & 14 & 13 & 12 & 11 & - & $12,50 \pm 0,75$ & 1,29 \\
\hline & Комбикорм, 2 день & 0 & 13 & 5 & 8 & 9 & $8,75 \pm 1,91$ & 3,30 \\
\hline & Комбикорм, 3 день & 13 & 18 & 8 & 4 & 3 & $9,20 \pm 3,15$ & 6,30 \\
\hline & Гидролизат, 1 день & 12 & 6 & 5 & 10 & 3 & $7,20 \pm 1,85$ & 3,70 \\
\hline & Гидролизат, 2 день & 10 & 7 & 9 & 6 & 5 & $7,40 \pm 1,04$ & 2,07 \\
\hline & Гидролизат, 3 день & 10 & 13 & 9 & 7 & 5 & $8,80 \pm 1,52$ & 3,03 \\
\hline
\end{tabular}

и рационе 7,20 11,85 шт. Во второй день $100,60 \pm 16,31$ секунды, при скорости питания $2,40 \pm 0,45$ экз./с и рационе $7,40 \pm 1,04$ шт. В третий день - 50,40 15,65 секунды, при скорости пита-

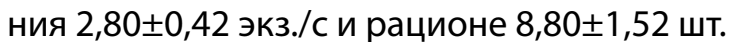

Отметим, что к концу опытов при кормлении рыбы гидролизатом продолжительность латентного времени питания снижалась, что свидетельствует о процессах привыкания к «новому» типу корма. Так, при кормлении гидролизатом за три дня эксперимента латентное время питания сократилось на 13 пунктов. При кормлении же комбикормом продолжительность латентного времени питания, наоборот, увеличилась в 2,2 раза. Под конец эксперимента значения этого показателя в опытной и контрольной группе различались в 2 раза (на гидролизат рыбы обращали внимание быстрее, чем на частички комбикорма, однако из-за большого разброса данных это различие недостоверно).

Время, проведённое на «кормовом пятне» молодью ленского осетра контрольной и опытной группы, также было различным. При кормлении комбикормом к 3-му дню оно сократилось в 5,3 раза, при кормлении гидролизатом, наоборот, увеличилось на 0,40 секунды. 
Частички комбикорма рыбы съедали быстрее, чем гидролизат.

Рацион изменился не сильно, однако рацион молоди ленского осетра опытной группы был чуть выше, чем контрольной. При кормлении комбикормом он убавился с 1-го по 3-й день на 26\%, а при кормлении гидролизатом увеличился на $19 \%$.

В таблице 4 приведены объединённые данные по типу корма (без учёта дня кормления).
Как показывают усреднённые данные, приведённые в таблице 4, в показателях пищевого поведения молоди ленского осетра не наблюдается достоверных отличий при использовании разных типов корма.

Для установления силы влияния исследованного фактора (тип корма) на отдельные показатели был проведён дисперсионный анализ, результаты которого приведены в таблице 5.

Таблица 4 - Показатели пищевого поведения молоди ленского осетра по типам корма

\begin{tabular}{|l|c|c|c|}
\hline \multicolumn{1}{|c|}{ Показатель } & $\mathrm{V}_{\text {лат }}$ & $\mathrm{V}_{\text {пит }}$ & $\mathrm{R}$ \\
\hline Комбикорм & $192,8 \pm 14,09$ & $5,88 \pm 2,10$ & $10,15 \pm 1,93$ \\
\hline Гидролизат & $71,53 \pm 17,95$ & $2,53 \pm 0,44$ & $7,8 \pm 1,47$ \\
\hline
\end{tabular}

Таблица 5 - Доля влияния фактора «тип корма» на исследованные показатели

\begin{tabular}{|l|c|c|c|}
\hline \multicolumn{1}{|c|}{ Показатель } & $\mathrm{V}_{\text {лат }}$ & $\mathrm{V}_{\text {пит }}$ & $\mathrm{R}$ \\
\hline Факториальная дисперсия $\left(\mathrm{C}_{\mathrm{x}}\right)$ & 1346,7 & 40,83 & 6,53 \\
\hline Остаточная дисперсия $\left(\mathrm{C}_{\mathrm{z}}\right)$ & 52527,46 & 655,46 & 523,33 \\
\hline Общая дисперсия $\left(\mathrm{C}_{\mathrm{y}}\right)$ & 53874,16 & 696,3 & 529,86 \\
\hline Доля влияния фактора, $\%$ & 2,50 & 5,86 & 1,23 \\
\hline
\end{tabular}

Примечание: *** - доля влияния достоверна при $\mathrm{P} \geq 0,999$.

Как показывает проведённый дисперсионный анализ, наибольшее влияние фактор «тип корма» оказывает на скорость питания $(5,86 \%)$ и латентное время (2,50\%). Рацион питания практически не зависит от типа корма, доля влияния фактора составила всего лишь 1,23\%.

\section{Выводы}

Ленский осётр предпочитает привычный для себя рацион - комбикорм. Тем не менее, при кормлении особей гидролизатом, продолжительность латентного времени питания с 1-го по 3-й день снижалась, что свидетельствует о процес- сах привыкания к «новому» типу корма. Рыба без затруднений обнаруживала пищевые объекты и схватывала частички гидролизата.

Белковый гидролизат - мощный натуральный ароматизатор, делающий вкус корма более привлекательным. Введение гидролизата рыбного протеина в состав стартового комбикорма оказывает положительный эффект на пищевое поведение молоди осетровых рыб, что позволяет легче адаптировать её в условиях интенсивного разведения. Использование стартовых комбикормов такого уровня позволит осуществлять выращивание личинок без применения «живых кормов» [6].

\section{תumepamypa}

1. Исаева, О.М. Вкусовая рецепция и пищевое поведение тропических помацентровых рыб [Текст] / О.М. Исаева, Т.В. Тинькова, А.О. Касумян // Морские биологические исследования: достижения и перспективы: сб. материалов Всеросс. науч.-практ. конф. с международ. участием, приуроченной к 145-летию Севастопольской биологической станции: в 3 томах. Т. 2. - Севастополь: Изд-во ЭКОСИ-Гидрофизика, 2016. С. 300-303.

2. Касумян, А.О. Вкусовые предпочтения и поведение тестирования вкусовых качеств корма у усатого гольца Barbatula barbatula (Balitoridae, Cypriniformes) [Текст] / А.О. Касумян, С.С. Сидоров // Вопросы ихтиологии. - 2010. - Т. 50. - № 5. - С. 708-720.

3. Смирнов, А.К. Влияние наличия пищи в зоне температурного оптимума на поведение молоди речного окуня Perca fluviatilis L. [Текст] / A.K. Смирнов // Вестник Астраханского государственного технического университета. Серия: Рыбное хозяйство. - 2013. - № 1. - С. 75-82. 
4. Гарина, Д.В. Влияние адреналина на некоторые характеристики пищевого поведения карася обыкновенного Carassius carassius (L.) [Текст] / Д.В. Гарина, Ю.В. Герасимов // Трофические связи в водных сообществах и экосистемах: матер. международ. конф. - Борок, 2003. - С. 18-19.

5. Флерова, Е.А. Технология получения гидролизата из рыбного сырья [Текст] / Е.А. Флерова, А.А. Богданова, Н.П. Баушева, Г.К. Ошкина // Многофункциональное адаптивное кормопроизводство: сб. науч. тр. М., 2018. - С. 136-140.

6. Грозеску, Ю.Н. Инновационные методы повышения эффективности кормления осетровых рыб на основе использования в рационах нетрадиционного кормового сырья и биологически активных препаратов [Текст]: диссертация / Ю.Н. Грозеску. - Астрахань: Астраханский государственный технический университет, 2016. - 307 c.

\section{References}

1. Isaeva, O.M. Vkusovaja recepcija i pishhevoe povedenie tropicheskih pomacentrovyh ryb [Tekst] / O.M. Isaeva, T.V. Tin'kova, A.O. Kasumyan // Morskie biologicheskie issledovanija: dostizhenija i perspektivy: sb. materialov Vseross. nauch.-prakt. konf. s mezhdunarod. uchastiem, priurochennoj k 145-letiju Sevastopol'skoj biologicheskoj stancii: v 3 tomah. T. 2. - Sevastopol': Izd-vo JeKOSI-Gidrofizika, 2016. S. 300-303.

2. Kasumyan, A.O. Vkusovye predpochtenija i povedenie testirovanija vkusovyh kachestv korma u usatogo gol'ca Barbatula barbatula (Balitoridae, Cypriniformes) [Tekst] / A.O. Kasumyan, S.S. Sidorov //Voprosy ihtiologii. 2010. - T. 50. - № 5. - S. 708-720.

3. Smirnov, A.K. Vlijanie nalichija pishhi v zone temperaturnogo optimuma na povedenie molodi rechnogo okunja Perca fluviatilis L. [Tekst] / A.K. Smirnov // Vestnik Astrahanskogo gosudarstvennogo tehnicheskogo universiteta. Serija: Rybnoe hozjajstvo. - 2013. - № 1. - S. 75-82.

4. Garina, D.V.Vlijanie adrenalina na nekotorye harakteristiki pishhevogo povedenija karasja obyknovennogo Carassius carassius (L.) [Tekst] / D.V. Garina, Yu.V. Gerasimov // Troficheskie svjazi v vodnyh soobshhestvah i jekosistemah: mater. mezhdunarod. konf. - Borok, 2003. - S. 18-19.

5. Flerova, E.A. Tehnologija poluchenija gidrolizata iz rybnogo syr'ja [Tekst] / E.A. Flerova, A.A. Bogdanova, N.P. Bausheva, G.K. Oshkina // Mnogofunkcional'noe adaptivnoe kormoproizvodstvo: sb. nauch. tr. - M., 2018. S. $136-140$.

6. Grozesku, Yu.N. Innovacionnye metody povyshenija jeffektivnosti kormlenija osetrovyh ryb na osnove ispol'zovanija $v$ racionah netradicionnogo kormovogo syr'ja i biologicheski aktivnyh preparatov [Tekst]: dissertacija / Yu.N. Grozesku. - Astrahan': Astrahanskij gosudarstvennyj tehnicheskij universitet, 2016. - 307 s.

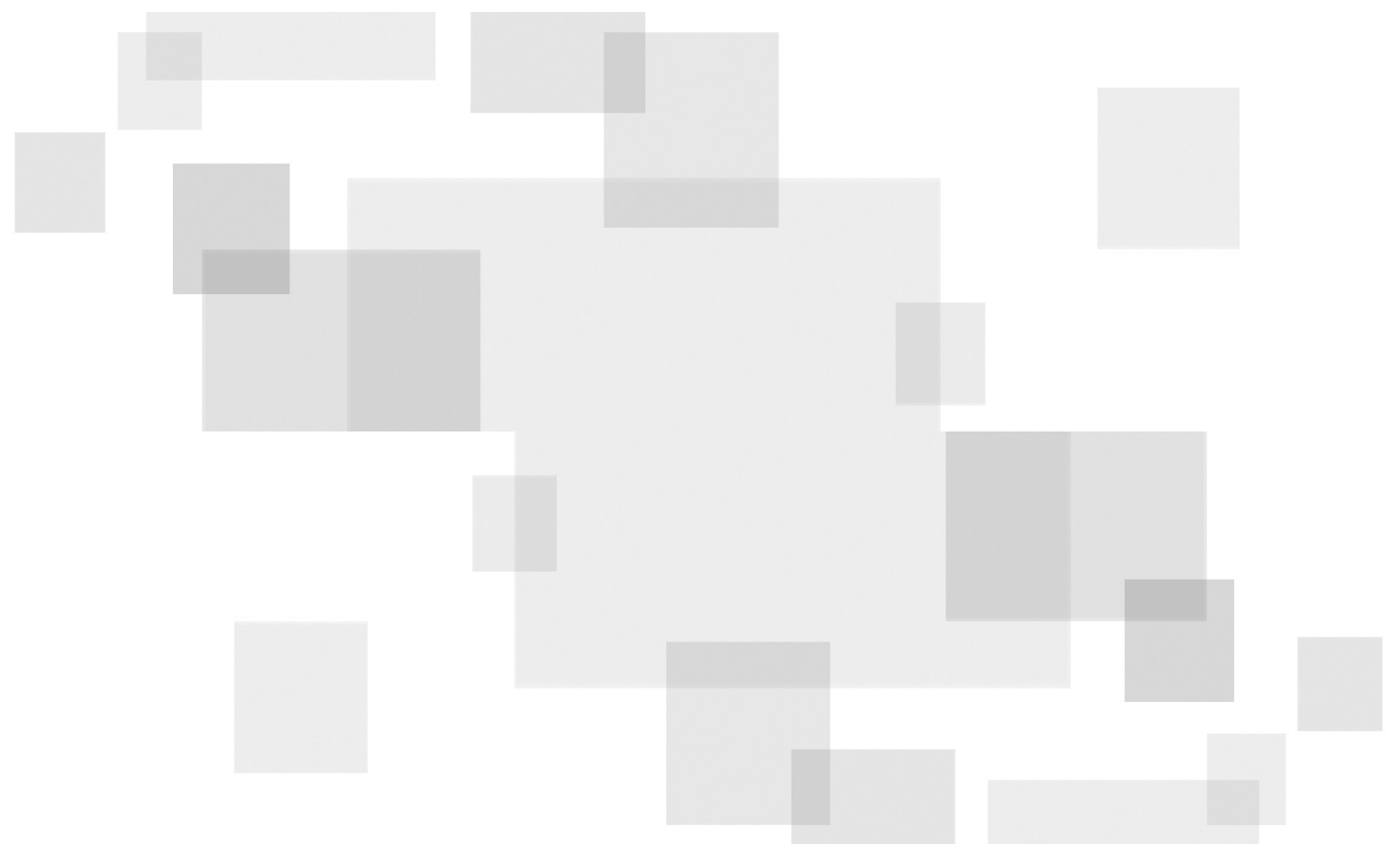

